\title{
The function and mechanisms underlying baboon 'contact' barks
}

\author{
DOROTHY L. CHENEY, ROBERT M. SEYFARTH \& RYNE PALOMBIT \\ Departments of Biology and Psychology, University of Pennsylvania \\ (Received 26 May 1995; initial acceptance 7 September 1995; \\ final acceptance 9 December 1995; MS. number: A7336)
}

\begin{abstract}
Free-ranging baboons, Papio cynocephalus ursinus, in the Okavango Delta, Botswana, often give loud 'contact' barks when separated from other group members. Although these calls appear to function to maintain contact between widely dispersed animals, individuals apparently do not give contact barks with the intent of informing others of their location. Females are more likely to give a contact bark in the $5 \mathrm{~min}$ after they themselves have called than in the $5 \mathrm{~min}$ after another female has called. Playback experiments suggest that females primarily 'answer' their close relatives' contact barks when they themselves are separated from other females or at the end of the group progression.
\end{abstract}

(C) 1996 The Association for the Study of Animal Behaviour

When moving through wooded areas, free-ranging chacma baboons, Papio cynocephalus ursinus, in the Okavango Delta, Botswana, often give loud, tonal barks (Fig. 1) that can be heard up to $200 \mathrm{~m}$ away. These barks are acoustically distinctive and can easily be distinguished, both spectrographically and by ear, from other calls in the baboons' vocal repertoire (R. Seyfarth \& D. Cheney, unpublished data). The barks appear to function as 'contact' calls, because they often seem to be exchanged between widely dispersed sub-groups or individuals. Although not previously described for other populations of savanna baboons in East or Southern Africa, the calls seem functionally and acoustically similar to the contact barks of forest Guinea baboons, P. c. papio (Byrne 1981), and mandrills, P. sphynx (Kudo 1987). Analogous loud calls occur in other primate species. In squirrel monkeys, Saimiri sciureus (Boinski 1991), and white-faced capuchins, Cebus capucinus (Boinski 1993), for example, loud trills seems to function not only to maintain group cohesion but also to initiate and set the direction of the group's movement. In some species, long distance calls may also serve as conditional recruitment signals that attract others to food. Foraging subgroups of both spider monkeys, Ateles geoffroyi (Chapman \& Levebre 1990), and chimpanzees,

Correspondence: D. L. Cheney, Department of Biology, University of Pennsylvania, Philadelphia, PA 19104, U.S.A. (email: cheney@cattell.psych.upenn.edu).
Pan troglodytes (Wrangham 1977; Clark \& Wrangham 1994), often give loud calls upon arriving at food resources. Typically, more calls are given at large food patches than at small ones.

Despite these observations, there is some doubt about whether loud calls have evolved specifically to alert others to food or to maintain contact between separated group members. For example, although calling sub-groups of spider monkeys are joined by other monkeys three times as often as sub-groups that remain silent, even calling sub-groups are joined only $17 \%$ of the time (Chapman \& Levebre 1990). In the case of chimpanzees, parties that call are not joined more than parties that remain silent (Clark \& Wrangham 1994). Furthermore, chimpanzees do not call more at times of high fruit production than at other times, and individuals that fail to alert others to food are not obviously punished. Observing that high-ranking males give more loud calls (or pant hoots) than other individuals, Clark \& Wrangham (1994) hypothesized that these calls function to signal the caller's status rather than to alert others to food (see also Mitani \& Nishida 1993).

Analyses of chimpanzee pant hoots highlight a problem that is common to all studies of long range 'contact' or 'food' calls: although listeners can potentially use the calls to maintain contact with signallers or to locate food resources, signallers may not call with the intent 


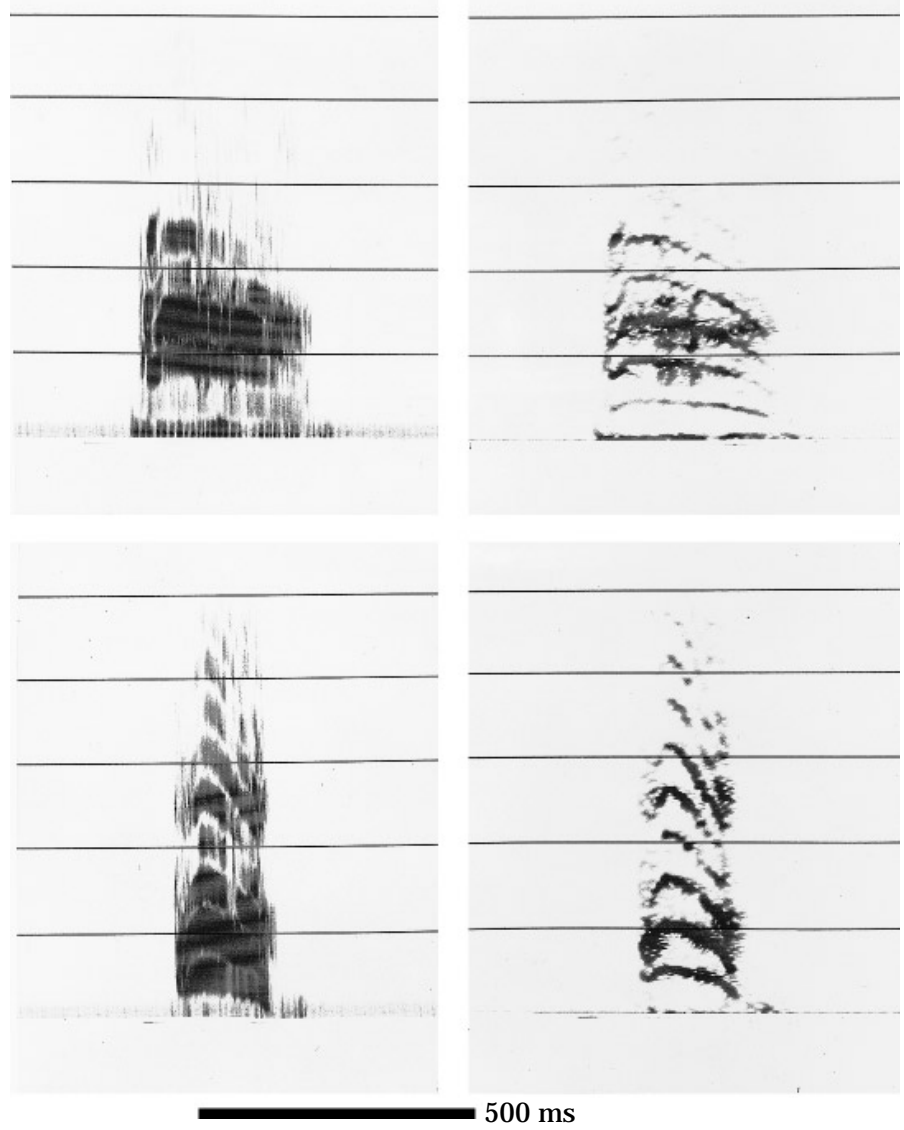

Figure 1. Wide-band (left, 300-Hz filter) and narrow-band (right, 45-Hz filter) sound spectrograms of contact barks given by two adult females. $X$-axis indicates time, $Y$-axis indicates frequency in units of $1 \mathrm{kHz}$.

of informing others. To date, for example, no studies have shown that individuals selectively answer the calls of separated individuals, or that they call more upon discovering a new food source than upon returning to a tree that was recently visited by many group members.

For those interested in the attribution of mental states by non-human species, the mechanisms underlying 'contact' calls are crucially important. An individual who attributes mental states to others recognizes that his own knowledge and beliefs may be different from theirs (e.g. Dennett 1988). Hypotheses based on mental state attribution predict that an individual will answer the contact calls of others, even when the individual is in the centre of the group progression and at no risk of becoming separated from others.
Current evidence suggests that monkeys do not attribute mental states to others, although the data for chimpanzees are more equivocal (reviewed in Byrne \& Whiten 1990; Cheney \& Seyfarth 1990; Povinelli 1993; van Hooff 1994). If monkeys are indeed incapable of understanding that other individuals' knowledge can be different from their own, they should be unable to recognize when other individuals have become separated from the group unless they themselves are also at risk of losing contact with others. Whether an individual calls, therefore, will be determined primarily by his own circumstances (e.g. separated or alone) rather than by the circumstances of those whom the caller appears to be answering.

In this paper, we first examine the context, rate and distribution of the 'contact' barks given by 
adult females in one troop of chacma baboons. We then discuss the pattern of apparent answers and describe a playback experiment that tested whether kin selectively answer each other's calls.

\section{PART I: OBSERVATIONS}

\section{Methods}

\section{Study area and subjects}

The study site lies in the Okavango Delta, a vast seasonal swamp created by the flood-plain of the Okavango River in northwestern Botswana. The habitat consists of flat, open grasslands interspersed by slightly elevated wooded patches ranging from less than one hectare to hundreds of hectares in size (Hamilton et al. 1976; Ross 1987). Each year, rainfall in Angola causes the Okavango and its tributaries to rise, creating a complex network of streams, marshes and lagoons. High water typically occurs between May and August. Wooded patches then become islands surrounded by marshy grassland that can be impassable in areas of heavy flooding. Baboons ford these grasslands to move from one wooded island to the next. The average size of a group's range is 450 ha (range 210-650; Hamilton et al. 1976).

Subjects were 23 sexually mature females that were part of a group of approximately 70 baboons. The group has been observed continuously since 1977 by Hamilton and colleagues (e.g. Bulger \& Hamilton 1988; Hamilton \& Bulger 1992). All animals are fully habituated to human observers on foot. Maternal relatedness for all natal animals is known. Here we define 'close kin' as maternal siblings and mothers and offspring.

\section{Observational protocol}

Continuous data on the contact barks given by adult females were gathered on 43 days during the winter months (June-August) of 1994. Supplementary data on the calling rates of juveniles and adult males were obtained on 28 days.

Data collection began when the group initiated its move from the sleeping site in the morning and continued for up to $2.5 \mathrm{~h}$. The termination time of data collection was pre-determined. Over $72 \mathrm{~h}$ of data on contact barks were gathered. By begin- ning our sampling only when the group initiated its morning move, we ensured that data on contact barks were gathered in roughly the same context each day, and we eliminated the possibility that calling bouts would appear to be clumped simply because some observations were based on periods when the group was coalesced and resting.

During data collection, two to four observers spread themselves throughout the group and devoted all their efforts to noting the identities of as many calling females as possible. By using several observers, we were able to ascertain the identity of the signaller for $92 \%$ of 1816 female contact barks.

Because it was often difficult to locate signallers when the group was moving rapidly through thickly wooded areas, we were unable simultaneously to note the locations and identities of all non-callers in the vicinity. The following analysis, therefore, does not consider the placement of signallers relative to other individuals, except in the case of playback experiments (see below).

We did, however, attempt to note the general position of signallers in the group progression. Because most members of the group were usually moving along the same general foraging route, it was relatively easy to determine the group's direction of movement, and hence the degree to which a particular individual might be lagging behind or in the vanguard of the main portion of the group. We determined whether an individual was in the first or last third of the group progression by drawing an imaginery line perpendicular to the direction of the group's travel route from the signaller's current location. So, for example, if approximately two thirds of the group had already crossed this imaginary line, the signaller was noted as being in the last third of the progression.

For ease of discussion, we use the term 'contact' bark to refer to the calls under study. A contact bark was designated as an 'answer' if it occurred within 5 min of a previous contact bark. These are descriptive rather than explanatory terms, and are not meant to carry any functional or intentional implications. We chose $5 \mathrm{~min}$ rather than $1 \mathrm{~min}$ as the interval in which an 'answer' might occur to avoid a spurious rejection of the hypothesis that individuals exchanged calls simply because we had not allowed a sufficiently long interval for them to do so. 
Table I. The acoustic features that were measured for each contact bark

\begin{tabular}{ll}
\hline Acoustic features & \multicolumn{1}{c}{ Definition } \\
\hline Call duration & Time at onset=T1. Time at end=T3. Duration=T3-T1. \\
$\begin{array}{l}\text { Peak position } \\
\text { Starting peak }\end{array}$ & Time at peak=T2. Peak position=(T2-T1)/duration. \\
Ending peak & Strongest frequency at T1=P1. \\
Maximum peak & Strongest frequency at T3=P3. \\
Average peak & Strongest frequency at T2=P2. \\
& Strongest frequency as revealed by a DFT spectrum using a 100 ms \\
Rise & window centred at the point of maximum amplitude (see text). \\
& Slope of the frequency increase from T1 to T2. \\
Fall & Rise=(P2-P1)/(T2-T1). \\
& Slope of frequency decline from T2 to T3. \\
Fundamental frequency $(\mathrm{F} 0)$ & Fall=(P2-P3)/(T2-T3). \\
& Average frequency difference between adjacent harmonics as shown \\
& on either narrow-band spectogram (Fig. 1$)$ or DFT spectrum (see text).
\end{tabular}

\section{Acoustic analysis}

To determine whether contact barks carried the potential for individual recognition, we performed an acoustic analysis of the contact barks given by 10 adult females. We obtained at least four highquality, tape-recorded calls for each female, for a total sample of 55 calls.

As a first step in this analysis, a subset of 10 calls was displayed on a Kay Electric Co. Digital Sonagraph (model DSP 5500) using frequency ranges of $0-8 \mathrm{kHz}$ and $0-16 \mathrm{kHz}$, and varying amplitude and mark levels to search for any energy above $5 \mathrm{kHz}$. Since little if any energy at these higher frequencies was found, all calls were subsequently digitized at a sampling rate of $12 \mathrm{kHz}$ (analysis range $0-6 \mathrm{kHz}$ ) using a Sun microsystems IPX workstation and WAVES software for signal processing and analysis, developed by David Talkin at AT\&T Bell Laboratories and available commercially from Entropic Speech Research Laboratory, Washington, D.C. WAVES software allows one to view simultaneously the waveform, wide-band spectrogram $(300 \mathrm{~Hz}$ filter $)$, and narrow-band spectrogram $(75 \mathrm{~Hz}$ filter) of each call, and to display discrete Fourier transformation (DFT) spectra of an entire call or any portion of it. We measured acoustic features in the temporal domain using either waveform or wideband spectrogram displays; measurements in the frequency domain were made using either the narrow-band spectrogram or DFT displays. To calculate the strongest frequency at call onset, call termination or the point of maximum frequency, we computed a DFT spectrum using a window size of $25 \mathrm{~ms}$. At this window size the DFT spectrum has a resolution of $40 \mathrm{~Hz}$. To obtain data on the strongest overall frequency averaged over the entire call, we computed a DFT spectrum using a $100 \mathrm{~ms}$ window centred at the point of maximum amplitude. At this window size the DFT spectrum has a resolution of $10 \mathrm{~Hz}$. As illustrated in the narrow-band spectrum in Fig. 1, many harmonics were visible in each call. To obtain an estimate of the call's fundamental frequency (F0), we selected a point at which the largest number of harmonics was visible, then calculated, wherever possible, the difference in frequency between adjacent harmonics and obtained the mean of these differences. Table I lists the acoustic features that were measured for each call.

\section{Results}

\section{The general context of contact barks}

To provide a framework for the observational and experimental results presented below, it is necessary to give a brief descriptive account of the context in which contact barks typically occurred. Females sometimes called at high rates when they were separated from their young offspring, even though they themselves might be in close proximity to many other individuals. Calls given in this context were not the focus of this study, however, and will not be discussed further here.

More than $80 \%$ of all other contact barks were given by individuals who were located in the last third of the group progression when the group 


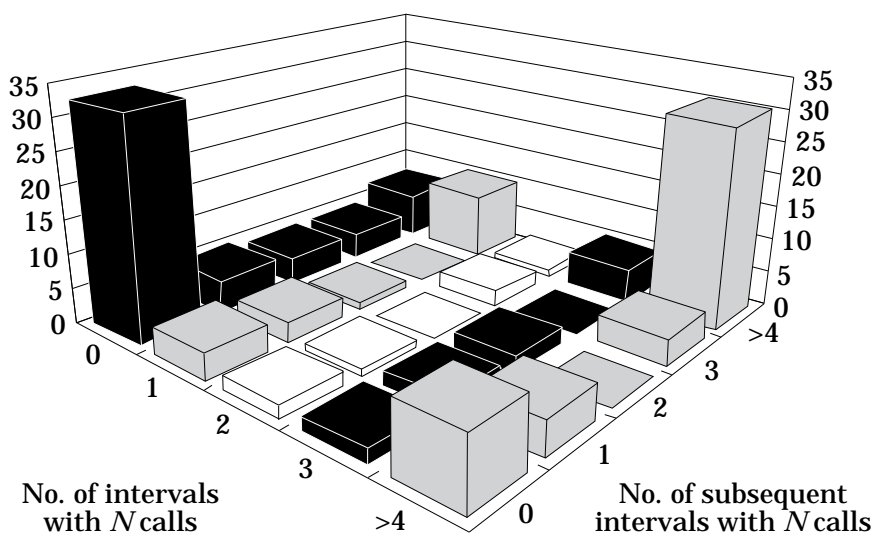

Figure 2. A comparison of the number of contact barks given by adult females in adjacent 10-min intervals. Data are based on an analysis of 137 adjacent time intervals.

was moving or feeding in woodland habitat. These individuals were not necessarily alone. Frequently, signallers, were feeding in the same tree as several other animals, many of whom might not be calling at all. Fewer than $1 \%$ of all contact barks occurred when the group was feeding on open flood plains or was tightly coalesced at a sleeping site.

Contact barks were also given at high rates when an individual or sub-group of individuals was separated by more than $200 \mathrm{~m}$ from the main body of the group and appeared to have lost contact with others. This occurred, for example, when sub-groups became separated during water crossings and slept on different islands (4 of 53 days when the group was first located at the sleeping site). The data discussed in this paper, however, were obtained only when the group initiated its morning move as a cohesive unit.

Although contact barks seemed to function to allow peripheral individuals to maintain contact with others, this hypothesis was difficult to test through observation alone because most calls were given when all group members were moving in roughly the same direction. When sub-groups were widely separated, they invariably rejoined after a period of time when individuals in one or both sub-groups had given many calls that were audible to the other. It is possible, however, that these sub-groups might eventually have rejoined in any case, even in the absence of contact barks.

Adult females and juveniles accounted for the majority of contact barks. When moving or feeding in the first $2 \mathrm{~h}$ after leaving the sleeping site, the 23 adult females called at a mean \pm SD rate of $25.9 \pm 21.6$ calls per hour, or at an individual mean rate of 1.1 calls per hour. The 29 juveniles and older infants ( $>6$ months of age) called at a rate of $31.2 \pm 24.0$ calls per hour, also at an individual mean rate of 1.1 calls per hour. In contrast, the 15 adult and subadult males called at a rate of $2.4 \pm 7.8$ calls per hour, at an individual mean rate of 0.2 calls per hour.

\section{The temporal pattern of contact barks}

Contact barks were sometimes given singly, in the absence of any other calls by adult females in the preceding or following $5 \mathrm{~min}$. More often, however, they appeared to occur in clumps, with more than one call occurring within a 5-min period. This clumping of calls reinforced the impression that females were exchanging and answering each other's calls in order to maintain contact in areas of limited visibility.

To test the hypothesis that contact barks were clumped in time, we divided the daily observation sessions into a series of contiguous, nonoverlapping 10-min intervals. Then, for each pair of adjacent intervals, we compared the number of calls in the first interval with the number of calls in the second. If females had given contact barks at random, then the number of calls in any two adjacent, non-overlapping intervals should have been independent and uncorrelated.

Results indicated a significant clumping of calls (Fig. $2 ; X^{2}=48.5, d f=16, P<0.01$ ). In other words, when there were no calls in the first $10-\mathrm{min}$ 


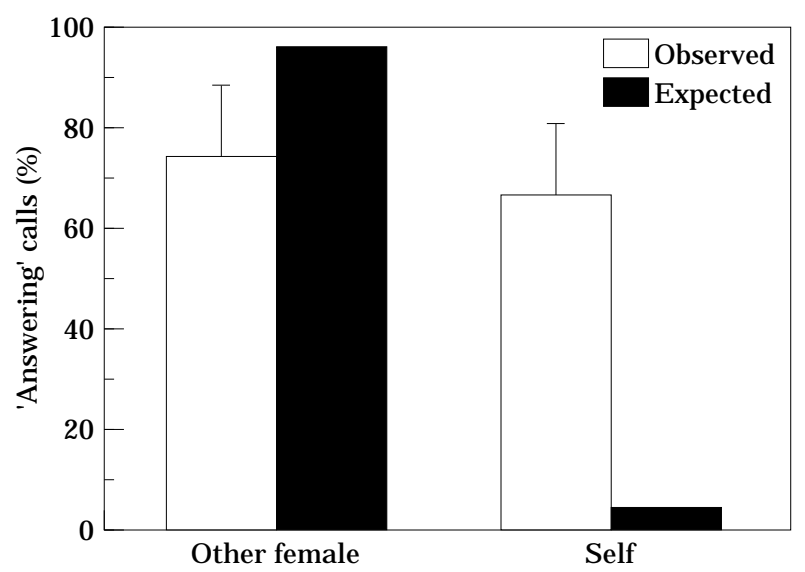

Figure 3. The mean proportion of each female's 'answering' calls that followed either a call by another female or a call by herself, compared with the expected proportion. Histograms show means and standard deviations for 23 females.

interval, there were generally also no calls in the second. Conversely, when there were many calls in the first interval there were typically also many calls in the second.

\section{The distribution of calls among adult females}

The temporal clumping of contact barks suggests, but does not prove, that females were exchanging calls with one another. Temporal clumping might have occurred, for example, because each female gave contact barks in bouts, without reference to whether other individuals were also calling. Alternatively, females may have exchanged calls but done so only with a small subset of individuals, such as closely related kin. It was difficult to test these possibilities through observation alone, because in the 5 min preceding any individual's contact bark she herself, another female, or a close relative might all have given several calls.

The group's 23 females gave 1662 calls that could be positively identified. Ninety-two per cent (1529) occurred in the $5 \mathrm{~min}$ following a call by either another female, the caller herself, or both another female and the caller herself. The fact that a contact bark might be preceded by several contact barks, some given in series by some individuals and some given singly by others, complicated efforts to determine the frequency with which females might have been expected to give 'answering' contact barks. As a first, crude pass at investigating this question, we simply calculated expected frequencies on the basis of each female's representation in the group.

If females had given 'answering' calls at random, then $96 \%(22 / 23)$ of each individual's calls should have occurred in the 5-min period following a call by another female, and 4\% (1/23) should have occurred following one of her own calls. In fact, on average $\pm \mathrm{SD}$, only $74 \pm 14 \%$ of each female's contact barks occurred in the 5-min period following a contact bark by another female (Fig. 3). Twenty-two of the 23 females gave fewer 'answering' calls to other females than would have been expected by chance (two-tailed binomial test, $P<0.001)$.

In contrast, an average of $66 \% \pm 14 \%$ of each female's contact barks occurred in the 5-min period following one of her own contact barks (Fig. 3). All 23 females 'answered', or repeated, themselves at least 10 times more than expected by chance $(P<0.001)$.

Even though females seemed to give fewer 'answering' barks than expected in response to the barks of other females, they might nevertheless have selectively answered the contact barks of their close adult relatives (either mothers, daughters or sisters). To test this hypothesis, we calculated, for each female with close relatives in the group, the number of her contact barks that were 'answered' by either an adult relative, a non-relative, or both. We then compared the actual number of 'answering' calls by relatives 
Table II. The number of contact barks given by adult females that was followed in the next $5 \mathrm{~min}$ by another call from either a relative or non-relative

\begin{tabular}{lcccc}
\hline & $\begin{array}{c}\text { No. of calls } \\
\text { answered by at least } \\
\text { one other female }\end{array}$ & $\begin{array}{c}\text { No. } \\
\text { answered } \\
\text { by kin }\end{array}$ & $\begin{array}{c}\text { Expected no. } \\
\text { answered } \\
\text { by kin }\end{array}$ & \\
\hline SL & 17 & 0 & 1.5 & - \\
SR & 2 & 0 & 0.2 & - \\
SY & 7 & 0 & 0.6 & - \\
SD & 6 & 5 & 0.5 & + \\
HL & 27 & 11 & 2.4 & + \\
HN & 18 & 3 & 1.6 & + \\
SH & 98 & 20 & 14.0 & + \\
SS & 77 & 27 & 2.4 & + \\
WR & 27 & 0 & 1.4 & - \\
LE & 46 & 5 & 2.3 & + \\
NI & 26 & 2 & 1.3 & + \\
RS & 13 & 3 & 2 & + \\
MR & 14 & 0 & 0.7 & - \\
AL & 26 & 4 & 1.3 & + \\
BL & 42 & 3 & 2.1 & + \\
JN & 56 & 4 & 2.8 & + \\
CD & 86 & 3 & 4.3 & - \\
& & & & \\
\hline
\end{tabular}

The actual number of 'answering' calls from relatives is compared with the number that would be expected by chance. Only females with at least one other close adult relative are included in the analysis. Close kin did not 'answer' their relatives more than would be expected by chance (two-tailed binomial test, $x=6, N=17, P>0.10$ ).

with the number that would have been expected had relatives 'answered' at a rate proportional to their representation among the group's 23 females. There was no strong evidence that females selectively exchanged calls with their adult kin. Although over half the females gave slightly more 'answering' calls than expected following their close relatives' calls, overall this trend was not significant (Table II).

\section{Individual variation in calling rates}

Among females, calling rates were negatively correlated with dominance rank $\left(r_{\mathrm{S}}=-0.435\right.$; two-tailed test, $P<0.05)$. Because systematic data on group progression orders (even in the absence of contact barks) were not gathered in this study, however, it was impossible to determine the cause of this correlation. It seems possible, for example, that low-ranking females were unable to gain access to clumped food resources until the food had been abandoned by higher-ranking individuals. If so, low-ranking females might have been more likely than others to be in the last part of the group progression, and therefore more at risk of losing contact with others. This question will be addressed in future research.

There was no evidence that calling rates were affected by a female's age or reproductive state. Females with independent but young offspring, for example, did not give contact barks at significantly higher rates than females with no offspring. The four females with infants aged between 6 months and 1 year called at a mean \pm SD rate of $1.5 \pm 1.0$ calls per hour. The five females with offspring aged between 1 to 3 years called at a rate of $0.6 \pm 0.3$ calls per hour, and the eight females with no young offspring gave a mean of $1.4 \pm 1.5$ calls per hour. None of these differences was statistically significant. Separation from young offspring, therefore, did not seem to occur sufficiently often to significantly affect females' calling behaviour. Because we did not systematically follow young juveniles, however, we could not determine whether females might have selectively 'answered' their young offspring more than their adult relatives on some of the occasions that their young offspring became separated from them. This question also remains to be investigated in future research.

\section{Acoustic analysis}

To test for individual differences in the acoustic features of contact barks, we conducted separate non-parametric Kruskal-Wallis one-way analyses of variance by ranks for each of the nine acoustic features listed in Table I. We found significant overall heterogeneity for eight of nine measures (Table III).

As a further test of individual distinctiveness, we carried out discriminant function analysis using caller identity as a dependent variable. Because predictor variables like length, starting frequency, and F0 had different scales of measurement, we transformed them to $z$-scores and then used these values in all subsequent analysis.

To begin, we performed a step-wise discriminant analysis using all nine measures listed in Table I as predictor variables. Three measures, maximum peak, ending peak and call length, each had an $F$-value greater than $4.5(P<0.001)$ and together accounted for $96.2 \%$ of the variability between individuals. Using these three variables alone, a discriminant function correctly assigned 
Table III. Results of Kruskal-Wallis one-way analyses of variance using the calls of nine different females and the nine acoustic features listed in Table I

\begin{tabular}{lcc}
\hline Acoustic feature & $H(d f=9)$ & $P$ \\
\hline Call duration & 37.071 & $<0.001$ \\
Peak position & 2.35 & $\mathrm{NS}$ \\
Starting peak & 42.856 & $<0.001$ \\
Ending peak & 41.065 & $<0.001$ \\
Maximum peak & 46.506 & $<0.001$ \\
Average peak & 22.22 & $<0.01$ \\
Rise & 17.60 & $<0.05$ \\
Fall & 34.85 & $<0.001$ \\
Fundamental frequency (F0) & 27.154 & $<0.001$ \\
\hline
\end{tabular}

$39(71 \%)$ of all 55 calls to the appropriate caller. For three females, all calls were assigned correctly; for three others, at least $75 \%$ of all calls were assigned correctly. Although it remains for future experiments to determine which feature(s) are the most important for distinguishing one individual's calls from another's, there appear to be several different acoustic features that listeners might use to identify individual callers.

\section{PART II: PLAYBACK EXPERIMENTS}

Our observations suggested that females gave barks primarily with reference to their own position in the group progression, when they were at the risk of losing contact with others. They appeared not to exchange calls with separated individuals, and there was no strong evidence that they selectively answered their relatives' contact barks. Interpretation of the observational data was confounded, however, by the fact that the calls of adult females typically occurred in clumps, with several females, including the signaller herself, often calling within a 5 -min period. To determine more systematically whether females selectively answered the contact barks of their close relatives, we designed playback experiments in which females' contact barks were played to their close kin.

\section{Methods}

We conducted playback experiments over a 2-month period. The playback stimuli consisted of the contact barks of 14 different females. These calls were played to 18 different subjects, each of whom was a close relative of the calling female. Two trials were conducted on each subject, for a total sample of 36. Most playbacks involving the same subject were separated by at least a week, although for one subject the separation between successive trials was 3 days. Subjects heard either two different calls from the same signaller $(N=16$ subjects) or one call from each of two different close relatives ( $N=2$ subjects).

Two observers participated in these experiments; one conducted the broadcast while the other filmed the subject's responses. To coordinate the timing of trials between the two observers, calls were played back to subjects at a mean distance of $20 \mathrm{~m}$, at an amplitude of 56-62 dB. This amplitude was chosen to mimic the amplitude of naturally occurring calls at $50 \mathrm{~m}$.

All experiments were conducted while the group was moving or foraging through wooded islands. The precise timing of playback experiments was dictated by four criteria. First, either an adult female or a juvenile had to have given at least one naturally occurring contact bark within the previous $5 \mathrm{~min}$. This prior condition ensured that we conducted all experiments at a time when some group members were potentially out of contact with one another and 'answering' barks might be expected to occur. Second, the subject could not herself have given a contact bark within the previous half hour. This criterion ensured that the subject would not be scored as 'answering' a playback simply because she was already motivated to call. Third, the female whose call was being played could not herself have called within the previous half hour, lest this too affect the subject's response. Finally, the subject had to be completely out of sight of and at least $50 \mathrm{~m}$ away from the female whose call was being played. In all trials, we noted the location of both the subject and the female whose call was being played. We also recorded the subject's relative position in the group progression and the identities of all individuals within $25 \mathrm{~m}$. The speaker was oriented towards the subject and was placed in the same direction as was the female whose call was being played. The subject's behaviour before and after playback was filmed with a video camera.

Because we predicted that females' responses to their relatives' contact barks would be strongly influenced by their own position in the group progression, we systematically varied this 


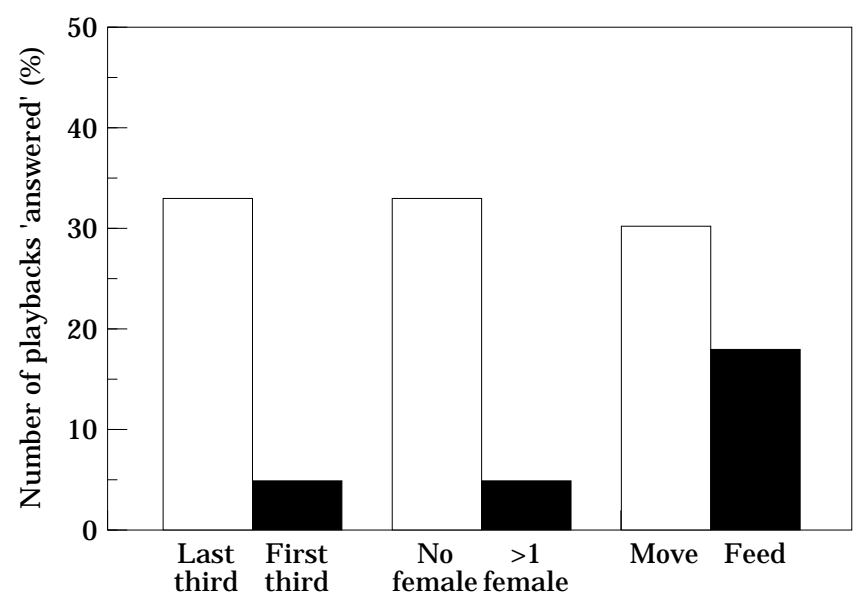

Figure 4. The proportion of playback experiments that elicited answering barks from subjects in different contexts. Histograms compare subjects in the last third versus the first two thirds of the group progression, in the vicinity of no other versus at least one other female, and moving as opposed to feeding. Data are based on 36 trials involving 18 subjects.

component across trials. We conducted 18 trials on females who were in the last third of the group progression, seven on subjects in the first third of the progression, and 11 on subjects in the middle third. In 12 trials, there were either no other individuals at all $(N=4)$ or no other adult females $(N=8)$ within $25 \mathrm{~m}$ of the subject. In six trials, one other female was within $25 \mathrm{~m}$ of the subject, and in another 18 trials at least two other females were nearby.

\section{Results}

In 20 of 36 trials $(56 \%)$, subjects oriented in the direction of the speaker following playback of their relative's contact bark. The mean duration of subjects' looks was $1.1 \mathrm{~s}$. Many subjects, therefore, showed no overt response to playbacks of contact barks.

In seven of 36 trials (19\%), subjects 'answered' their relative's contact bark by giving at least one contact bark themselves within the next $5 \mathrm{~min}$. In one additional trial, the subject called in the 7th min after playback. In no case did other, unrelated females in the vicinity respond to the playbacks with a call. Contact barks were the only type of call elicited by the playback experiments.

The fact that playbacks of contact barks elicited at least some vocal responses makes these experiments qualitatively different from any of the other playback experiments that have been conducted with this group of baboons. No vocal responses have ever been elicited in playback experiments involving the baboons' grunts, fear barks or screams (Cheney et al. 1995a, b; R. Palombit, R. Seyfarth \& D. Cheney, unpublished data).

At first inspection, results might be taken as weak evidence for the selective exchanging of contact barks among close kin. Closer examination, however, reveals that subjects 'answered' playbacks of their relatives' barks primarily when they themselves were lagging behind in the group progression and separated from other females. Subjects who were in the last third of the group progression were significantly more likely to answer their relatives' contact barks than were subjects in the first two thirds (Fig. 4; $X^{2}=4.43$, $P<0.05)$. Similarly, subjects were significantly more likely to give answering barks when there was no other female within $25 \mathrm{~m}$ than if there was at least one other female nearby (Fig. $4 ; X^{2}=5.86$, $P<0.05)$. Subjects were also more likely to call when the group was moving rather than feeding, though not significantly so. There was no indication that the placement of the speaker relative to the subject (e.g. behind or in front of her in the group progression) affected the probability of a response. Results from the playback experiments, therefore, support observational 
data in suggesting that females gave contact barks primarily with reference to their own position.

\section{DISCUSSION}

Although it is always difficult, regardless of the species being tested, to determine the precise meaning of a call to signallers and recipients, some speculation about the function and meaning of contact barks seems possible. First, long distance calls that function to maintain contact among kin or other group members must necessarily be individually distinctive. Although there have been few experimental tests of individual recognition in long-distance calls (cf. Waser 1977; Snowdon \& Hodun 1985), all acoustical analyses to date indicate the potential for individual recognition (e.g. Chapman \& Weary 1990; Mitani \& Brandt 1994). In this study, too, many acoustic features could have allowed a listener to distinguish between the contact barks of different individuals (Table III). Individuals could, therefore, potentially exchange calls selectively with particular other group members.

Second, when subjects responded vocally to playbacks of contact barks, they always responded by giving contact barks rather than other types of calls. In contrast, they never gave contact barks in response to playbacks of any other call types. It therefore seems probable that females interpreted contact barks as being restricted to the context of separation or loss of contact with others.

Third, signallers were more likely to give contact barks after they themselves had called than after other females had called (Fig. 3), and they appeared to 'answer' their relatives' calls primarily when they themselves were at risk of becoming separated from others (Fig. 4). Contact barks, therefore, seemed more often to reflect the signaller's own state and position than the state and position of her audience.

Not all contact barks, however, were given by individuals that were in the last third of the group progression or separated from other females. The fact that individuals also called when they were near other adult females suggests that the proximate cause of contact barks was not simply separation from the group in general. Instead, females may have given contact barks primarily when they were separated from particular individuals.
Social relationships within baboon groups are sharply differentiated, and females do not interact at similar rates with all individuals. Instead, females preferentially associate with their offspring, their matrilineal kin and, especially when they have young infants, particular adult males (Seyfarth 1976, 1978; Smuts 1985; Saunders 1988; R. Palombit, R. Seyfarth \& D. Cheney, unpublished data). Individuals towards the end of the group progression may call at high rates because, more often than those at the centre or vanguard, they have lost contact with their preferred associates. Similarly, those at the centre might also give contact barks when a particular male, a close relative, or an infant was out of sight. This interpretation might explain why unrelated females never responded to playbacks of contact barks, and why there was a slight tendency for adult kin to respond to each other's calls. It might also explain why even females in close proximity to other individuals sometimes gave repeated contact barks if their young offspring were out of sight. Future research will attempt to investigate this hypothesis more systematically.

The results reported here for the contact barks of baboons are consistent with those reported for many other species of birds and mammals. Despite numerous tests of the hypothesis that foraging animals selectively share information about food or their respective locations with particular individuals, no study has found evidence that signallers deliberately provide information to others, or that they recognize whether their audience is ignorant or already knowledgeable about the information being conveyed. For example, although carrion birds and bats that feed at widely dispersed food sources could potentially share information at common roosting sites, individuals apparently locate food either by following others or by simply finding it themselves (e.g. carrion crows, Corrus corone: Richner \& Marclay 1991; turkey vultures, Cathartes aura: Prior \& Weatherhead 1991; evening bats, Nycticeius humeralis: Wilkinson 1992; red kites, Milvus milvus: Hiraldo et al. 1993).

There is a similar lack of evidence for intentional information sharing by non-human primates (cf. Hauser \& Marler 1993 for a possible exception in rhesus macaques, Macaca mulatta). Although progression, contact and food calls may function to inform others, the proximate cause of the calls appears to be the current state or status 
of the signaller. Capuchins and squirrel monkeys give progression calls when they themselves are either moving or about to move (Boinski 1991, 1993). Spider monkeys call when they arrive at a fruiting tree, but there is no evidence that calling is affected by the presence or composition of nearby sub-groups (Chapman \& Levebre 1990). Although chimpanzees often give pant hoots upon arriving at large unoccupied fruiting trees, the fruiting status of the tree and the knowledge or ignorance of nearby companions appear to have little influence on calling behaviour (Clark \& Wrangham 1994).

An individual that calls to maintain contact with separated group members should answer the calls of others even when she is in the centre or vanguard of the group progression. The ability to answer others, however, requires that individuals be able to recognize that other group members can be at risk of losing contact with others even when they themselves are not. The fact that baboons do not selectively answer the calls of other individuals suggests that contact barks are not given with the intent of sharing information. Although the calls may ultimately function to allow individuals to avoid separation from others, they appear primarily to reflect the signaller's own attempts to maintain contact with particular other individuals.

\section{ACKNOWLEDGMENTS}

We thank the Office of the President and the Department of Wildlife and National Parks of the Republic of Botswana for permission to conduct research in the Moremi Reserve. We are grateful to W. J. Hamilton III for logistical support and access to background data. Mokopi Mokopi and C. Seyfarth provided invaluable assistance in the field by locating and identifying calling animals. F. Norman helped with data analysis. We also thank J. Mitani and J. Silk for comments on earlier drafts of the manuscript. This research was supported by grants from the National Geographic Society, the Research Foundation of the University of Pennsylvania, the Institute for Research in Cognitive Science at the University of Pennsylvania, and NIH grant HD-29433 to D.C. and R.S. R.P. was supported by an NIMH postdoctoral fellowship, the Leakey Foundation, the Wenner-Gren Foundation and NIH grant HD-29433.

\section{REFERENCES}

Boinski, S. 1991. The coordination of spatial position: a field study of the vocal behaviour of adult female squirrel monkeys. Anim. Behav., 41, 89-102.

Boinski, S. 1993. Vocal coordination of troop movement among white-faced capuchin monkeys, Cebus capucinus. Am. J. Primatol., 30, 85-100.

Bulger, J. \& Hamilton, W. J. 1988. Inbreeding and reproductive success in a natural chacma baboon, Papio cynocephalus ursinus, population. Anim. Behav., 36, 574-578.

Byrne, R. W. 1981. Distance vocalisations of Guinea baboons (Papio papio) in Senegal: an analysis of function. Behaviour, 78, 283-313.

Byrne, R. W. \& Whiten, A. 1990. Computation and mindreading in primate tactical deception. In: Natural Theories of Mind (Ed. by A. Whiten), pp. 241-259. Oxford: Blackwell Scientific Publications.

Chapman, C. A. \& Levebre, L. 1990. Manipulating foraging group size: spider monkey food calls at fruiting trees. Anim. Behav., 39, 891-896.

Chapman, C. A. \& Weary, D. M. 1990. Variability in spider monkeys' vocalizations may provide basis for individual recognition. Am. J. Primatol., 22, 279-284.

Cheney, D. L. \& Seyfarth, R. M. 1990. How Monkeys See the World: Inside the Mind of Another Species. Chicago: University of Chicago Press.

Cheney, D. L., Seyfarth, R. M. \& Silk, J. B. 1995a. The responses of female baboons (Papio cynocephalus ursinus) to anomalous social interactions: evidence for causal reasoning? J. comp. Psychol., 109, 134-141.

Cheney, D. L., Seyfarth, R. M. \& Silk, J. B. 1995b. The role of grunts in reconciling opponents and facilitating interactions among adult female baboons. Anim. Behav., 50, 249-257.

Clark, A. P. \& Wrangham, R. W. 1994. Chimpanzee arrival pant-hoots: do they signify food or status? Int. J. Primatol., 15, 185-205.

Dennett, D. C. 1988. The intentional stance in theory and practice. In: Machiavellian Intelligence: Social Expertise and the Evolution of Intelligence in Monkeys, Apes, and Humans (Ed. by R. W. Byrne \& A. Whiten), pp. 28-44. Oxford: Oxford University Press.

Hamilton, W. J. \& Bulger, J. 1992. Facultative expression of behavioral differences between one-male and multimale savanna baboon groups. Am. J. Primatol., 28, 61-71.

Hamilton, W. J., Buskirk, R. E. \& Buskirk, W. H. 1976. Defense of space and resources by chacma (Papio ursinus) baboon troops in an African desert and swamp. Ecology, 57, 1264-1272.

Hasuer, M. D. \& Marler, P. 1993. Food-associated calls in rhesus macaques (Macaca mulatta). II. Costs and benefits of call production and suppression. Behav. Ecol., 4, 206-212.

Van Hooff, J. A. R. A. M. 1994. Understanding chimpanzee understanding. In: Chimpanzee Cultures (Ed. by R. W. Wrangham, W. C. McGrew, F. B. M. de Waal \& P. G. Heltne), pp. 267-284. Cambridge, Massachusetts: Harvard University Press.

Hiraldo, F., Heredia, B. and Alonso, J. C. 1993. Communal roosting of wintering red kites, Milvus 
milvus: social feeding strategies for the exploitation of food resources. Ethology, 93, 117-124.

Kudo, H. 1987. The study of vocal communication of wild mandrills in Cameroon in relation to their social structure. Primates, 28, 289-308.

Mitani, J. \& Brandt, K. L. 1994. Social factors influence the acoustic variability in the long-distance calls of male chimpanzees. Ethology, 96, 233-252.

Mitani, J. \& Nishida, T. 1993. Contexts and social correlates of long-distance calling by male chimpanzees. Anim. Behav., 45, 735-746.

Povinelli, D. J. 1993. Reconstructing the evolution of mind. Am. Psychol., 48, 493-509.

Prior, K. A. \& Weatherhead, P. J. 1991. Turkey vultures foraging at experimental food patches: a test of information transfer at communal roosts. Behav. Ecol. Sociobiol., 28, 385-390.

Richner, H. \& Marclay, C. 1991. Evolution of avian roosting behaviour: a test of the information centre hypothesis and of a critical assumption. Anim. Behav., 41, 433-438.

Ross, K. 1987. Okavango: Jewel of the Kalahari. New York: Macmillan.
Saunders, C. D. 1988. Ecological, social, and evolutionary aspects of baboon (Papio cynocephalus) grooming behavior. Ph.D. thesis, Cornell University, Ithaca, New York.

Seyfarth, R. M. 1976. Social relationships among adult female baboons. Anim. Behav., 24, 917-938.

Seyfarth, R. M. 1978. Social relations among adult male and female baboons. II. Behavior throughout the female reproductive cycle. Behaviour, 64, 227-247.

Smuts, B. B. 1985. Sex and Friendships in Baboons. New York: Aldine.

Snowdon, C. T. \& Hodun, A. 1985. Troop-specific responses to long calls of isolated tamarins (Saguinus mystax). Am. J. Primatol., 8, 205-213.

Waser, P. 1977. Individual recognition, intragroup cohesion, and intergroup spacing: evidence from sound playback to forest monkeys. Behaviour, 60, $28-74$.

Wilkinson, G. S. 1992. Information transfer at evening bat colonies. Anim. Behav., 44, 501-518.

Wrangham, R. W. 1977. Feeding behaviour of chimpanzees in Gombe National Park, Tanzania. In: Primate Ecology (Ed. by T. H. Clutton-Brock). New York: Academic Press. 